pessimismo da razão e o otimismo da ação para a classe trabalhadora em tempos de golpe, 2017. Goiânia. Anais...Goiânia: UFG, 2017, p.146-160. PEDRO. Entrevista concedida à Angela dos Santos Machado. Teodoro Sampaio, 2018

PIGNATI, W.A. Acidente rural ampliado: o caso das "chuvas" de agrotóxicos sobre a cidade de Lucas do Rio Verde - MT. Ciência e Saúde Coletiva, 12(1):105-114, 2007

RABELLO, D. Campesinato e agrohidronegócio canavieiro no Pontal do Paranapanema: os desafios para a transição agroecológica. Monografia. Universidade Estadual Paulista "Júlio de Mesquita Filho", Presidente Prudente, 2014

SILVA, J.M. 'Não me chame de senhora, eu sou feminista'!: posicionalidade e reflexibilidade na produção geográfica de Doreen Massey. GEOgraphia. vol.19, nº40, Niterói, mai./ago., 2017.

SOBREIRO FILHO, J. O movimento em pedaços e os pedaços em movimentos: da ocupação do Pontal do Paranapanema à dissensão nos movimentos socioterritoriais camponeses. $546 \mathrm{f}$. Dissertação (mestrado em Geografia). Universidade Estadual Paulista "Júlio de Mesquita Filho", Presidente Prudente, 2013.

THOMAZ JÚNIOR, A. Por trás dos canaviais, os "nós" da cana: A relação capital $\mathrm{x}$ trabalho e o movimento sindical dos trabalhadores na agroindústria canavieira paulista. São Paulo: Annablume, 2002.

\section{APOSENTADORIA ENTRE OS ASSENTADOS RURAIS: CONQUISTAS, BENEFÍCIOS E BLOQUEIOS}

Rubens de Oliveira Eliziário Vera Lucia Silveira Botta Ferrante ${ }^{2}$ Hildebrando Herrmann ${ }^{3}$

Resumo: O objetivo deste artigo foi discutir a previdência social rural no Brasil e as particularidades do segurado especial no Assentamento Reage Brasil, Bebedouro-SP. Foram aplicados questionários estruturados e entrevistas semiestruturadas às 57 pessoas de 42 lotes que recebem benefícios previdenciários e em 10 lotes que não dispõem do benefício previdenciário, além de serem consultados dados de caderneta de campo de 2014 e bancos de dados da Fundação ITESP. Os resultados revelam contradições e erros de interpretação na aplicação dos direitos previdenciários ao segurado especial. Constatou-se também que após a obtenção do benefício, ocorrem mudanças benéficas na vida do assentado. Os recursos são utilizados para a compra de alimentos, insumos agropecuários, roupas e remédios, reforma da casa, viagem para casas de filhos e realização de empréstimo consignado. A maioria dos benefícios, que tem melhorado a qualidade de vida das famílias, só foi conseguida via ação judicial. O tema ganha importância, não só porque a reforma da previdência tem sido matéria de discussão continuada e controversa da conjuntura brasileira, mas porque é pouco estudada na significativa produção acadêmica voltada a assentamentos rurais.

Palavras-ChaVE: Assentamentos rurais; Previdência Social Rural; Segurado Especial.

Mestre pelo Programa de Pós-Graduação (PPG) em Desenvolvimento Territorial e Meio Ambiente da Universidade de Araraquara - UNIARA. Advogado e Técnico em Desenvolvimento Agrário da Fundação ITESP. E-mail: rubenseliziario@yahoo.com.br.

2Docente e Coordenadora do PPG em Desenvolvimento Territorial e Meio Ambiente da UNIARA. E-mail: vbotta@techs.com.br.

Docente do PPG em Desenvolvimento Territorial e Meio Ambiente da UNIARA. E-mail: dtmeioambiente@ uniara.com.br. 
ABSTRACT: The objective of this article was to discuss rural social security in Brazil and the particularities of the special insured in Settlement Reage Brasil, Bebedouro-SP. Structured questionnaires and semi-structured interviews were applied to 57 people from 42 lots that receive social security benefits and in 10 lots that do not have the social security benefit, in addition to being consulted data from the field book of 2014 and ITESP Foundation databases. The results reveal contradictions and errors of interpretation in the application of social security rights to the special insured. It was also found that after obtaining the benefit, beneficial changes take place in the life of the settler. The funds are used for the purchase of food, agricultural inputs, clothing and medicines, home renovation, travel to children's homes and payroll loan. Most of the benefits, which have improved the quality of life of the families, were only achieved through legal action. The issue becomes important, not only because pension reform has been a subject of continuous and controversial discussion of the Brazilian scenario, but because it is little studied in the significant academic production aimed at rural settlements.

KEYWORDS: Rural settlements; Rural social security; Special insured.

\section{INTRODUÇÃo}

Este artigo tratou dos aspectos sociais, econômicos, fundiários e previdenciários do Assentamento Reage Brasil no Município de Bebedouro no Estado de São Paulo.

O assentamento Reage Brasiléum assentamentoestadualde responsabilidade da Fundação Instituto de Terras do Estado de São Paulo "José Gomes da Silva" (ITESP) ${ }^{4}$. Está localizado no município de Bebedouro, região norte do estado de São Paulo, que faz parte da Bacia Hidrográfica Baixo Pardo/Grande.

O assentamento, que foi criado oficialmente em setembro de 1998, é composto por 84 lotes familiares de 8,5 ha de área agrícola, em média, e de 3,5 ha de áreas destinadas para manejo florestal, totalizando 671.761 hectares de área agrícola, 263.421 ha de áreas destinadas à reserva florestal legal e preservação permanente e 295,73 ha de área destinada para manejo florestal (OLIVEIRA, 2006). Nestes 42 lotes moram 57 pessoas beneficiadas pela previdência e que recebem algum tipo de benefício previdenciário:

aposentadoria, pensão ou ambos. Nos demais lotes, seus possuidores, ou ${ }^{4}$ O ITESP é o órgão estadual implementador da política agrária em São Paulo, com atuação na instalação de projetos de assentamentos em áreas públicas estaduais e terras devolutas. não atingiram a idade de aposentadoria ou simplesmente não fazem jus aos benefícios da Previdência Social como pensionistas. Deve-se ressaltar que esses benefícios previdenciários estão distribuídos da seguinte forma: 30 mulheres, das quais 3 são agregadas e 33 homens, dos quais 3 são agregados.

O objetivo deste artigo foi promover uma discussão sobre a previdência social rural no Brasil e as particularidades do segurado especial em um território de um assentamento de reforma agrária, cuja região é dominada pelo agronegócio, com ênfase para dois aspectos particulares: o tratamento discriminatório praticados pelos agentes públicos e a dificuldade para obtenção desses direitos constitucionais, em que pese a legalidade dos requerimentos apresentados.

\section{A TRAJETÓRIA DA SEGURIDADE SOCIAL ATRAVÉS DO TEMPO: UM RESGATE} HISTÓRICO

Na Roma antiga, havia o "pater famílias”, que tinha a obrigação de prestar assistência aos servos e clientes necessitados. O soldado romano guardava duas sétimas partes do seu salário para quando se "aposentasse". Recebia além do seu saldo um pedaço de terra, o que também era uma forma de proteção previdenciária.

$\mathrm{Na}$ Inglaterra, em 1601, editou-se a "Poor Relief Act", foi o primeiro documento legislativo de grande importância, no que diz respeito à Previdência Social. Era uma lei de amparo aos pobres. Regulamentava a instituição de auxílios e socorros públicos aos necessitados. Previa uma contribuição obrigatória dos ocupantes e usuários de terras para auxílio aos indigentes.

Em 1897, foi instituído o "Workmen Compensation Act", seguro obrigatório contra acidentes do trabalho, onde o trabalhador tinha o direito a uma indenização, caso ocorresse algum acidente. Em 1907, foi estabelecido o sistema de assistência ao idoso. Em 1908, foi concedida pensão aos maiores de setenta anos, independente de contribuição. Em 1911, foi determinada a aplicação de um sistema compulsório de contribuições sociais a cargo do empregador, empregados e do Estado.

Em 1941, por meio do plano Beveridge ${ }^{5}$, foi implantado um programa de prosperidade política e social, que garantia recurso suficiente para que se algum trabalhador, por qualquer motivo, não pudesse trabalhar seria

${ }^{5} \mathrm{O}$ plano de Lord Beveridge tinha como objetivos: unificar os seguros sociais existentes; tríplice forma de custeio; estabelecer o princípio da universalidade e igualdade de proteção. Este plano visava atingir a todas as pessoas, estabelecer o princípio da universalidade e igualdade de proteção. Este plano visava atingir a todas as pessoas,
mesmo aquelas que não eram empregadas. Inspirado neste plano, em 1944, o governo inglês apresentou o plano de previdência social que foi implantado, em 1946. 
coberto pelo seguro social.

Foi na Alemanha que teve origem o primeiro ordenamento legal que tratou da Previdência Social. Para atenuar tensões da classe trabalhadora, o Chanceler Ottan Von Bismack introduziu uma série de seguros sociais. Em 1883, foi introduzido o seguro-doença que era custeado por empregados, empregadores e Estado; em 1884, foi instituído o seguro de acidente do trabalho, pago pelos empregadores; em 1889, foi criado o seguro de invalidez e velhice, de responsabilidade dos trabalhadores, empregadores e Estado. Além disso, todos os trabalhadores que recebessem até 2.000 marcos anuais eram obrigados a se filiar a uma seguradora ou a entidades de socorros mútuos. Estas medidas tinham caráter eminentemente político. Devido a decorrência da crise industrial, os movimentos socialistas encontravam-se fortalecidos e a medida visava obter a consagração social Isto culminou com o surgimento do Código de seguro social alemão, em 1911 (MEIRELLES, 2009).

Somente os empregados tinham direito à proteção social, desde que contribuíssem. Este modelo foi denominado Bismarckiano. Após os seguros sociais, em 1919, a Constituição de Weimar determinava que o Estado se incumbiria da subsistência do cidadão alemão, caso não houvesse oportunidade aos trabalhadores de ganhar a vida com um trabalho produtivo. foi criado o plano chamado de cobertura social. Era obrigatório para os trabalhadores do setor

Nos Estados Unidos, com a influência da política do Welfare State, a evolução da Previdência Social se deu quando o Presidente Franklin Roosevelt, para tentar resolver a crise econômica de 1929, introduziu o "New Deal", estado do bem-estar social com o objetivo de combater a miséria com um conjunto de políticas estatais, para criar novos empregos e uma rede de previdência e saúde pública. Teve, através do seu Congresso, aprovado o Social Security Act, amparando idosos e instituindo, também, o auxílio-desemprego (MEIRELLES, 2009).

Este modelo foi considerado Beveridgeano, pelo qual todos os cidadãos tinham direito à seguridade social, independente de contribuição. Há diferença entre o sistema bismarckiano e o beveridgeano. Este último é universal, protege todos os cidadãos, já o bismarckiano é um seguro social, protegendo somente aqueles que contribuem para o sistema.

O período de universalização da Previdência corresponde, ao período de expansão geográfica dos Estados Unidos, tendo como ápice o Tratado de
Versalhes de 1919, que criou a Organização Internacional do Trabalho(OIT).

A Organização Internacional do Trabalho (OIT) foi criada em 1919. Tal órgão passou a evidenciar a necessidade de um programa sobre previdência social, aprovando-o em 1921. Várias convenções vieram a tratar da matéria, como a de $\mathrm{n}^{\mathrm{o}} 12$, sobre acidentes do trabalho na agricultura, de 1921; a Convenção n 17 (1927), sobre "indenização por acidente de trabalho", e outras (MARTINS, 2010, p. 5).

O México foi o primeiro país a incluir o seguro social em seu texto constitucional, isto na Constituição de 1917, tratado em seu artigo 123. Assim, surgiu uma nova fase no mundo, denominada constitucionalismo social, onde as constituições dos países começaram a ter, em seus textos, os direitos sociais, trabalhistas, econômicos e previdenciários. Em 1948, foi promulgada a Declaração Universal dos Direitos Humanos do Homem que, em seu artigo XXV, determinava:

todo homem tem direito a um padrão de vida capaz de assegurar, a si e à sua família, bem-estar, inclusive alimentação, vestuário, habitação, cuidados médicos e os serviços sociais indispensáveis, o direito à seguridade no caso de desemprego, doença, invalidez, viuvez, velhice, ou outros casos de perda dos meios de subsistências em circunstâncias fora de seu controle.

Assim, em todos os países foram sendo elaborados e instituídos programas de seguridade social.

RETROSPECTIVA HISTÓRICA DA PREVIDÊNCIA SOCIAL RURAL NO BRASIL: O PROCESSO dE CONQUiSTA DA CIDADANIA

$\mathrm{O}$ direito à seguridade social no Brasil foi construído por meio de muitas lutas e conquistas dos trabalhadores. É o resultado de um processo contínuo, que demandou o desenvolvimento de novos conceitos e instituições. Gradativamente, novos sujeitos foram sendo reconhecidos como possuidores de direitos e, nesse processo, a última categoria a obter o reconhecimento foi a do trabalhador em regime de agricultura familiar. Esse fato é paradoxal porque tendo sido o trabalhador rural uma das primeiras categorias profissionais do Brasil, foi a última a ter seus direitos reconhecidos.

O direito da seguridade social, ou seja, os direitos previdenciários dos 
trabalhadores urbanos, têm como marco a fundação da Santa Casa de Misericórdia de Santos, que ${ }^{6}$; previa a entrega de prestações assistenciais e um plano de pensão para seus funcionários, os empregados das Ordens Terceiras, além de outras instituições que mantinham hospitais, asilos, orfanatos e casas de amparo a seus associados e desvalidos (MEIRELLES, 2010). Contudo, somente no ano de 1945 é que teve início os direitos previdenciários dos trabalhadores rurais brasileiros.

Em 1963, praticamente surgiu uma mini Consolidação das Leis do Trabalho (CLT) rural, por meio da Lei n. 4.214, de 1963, denominada de Estatuto Rural, que tratou dos direitos individuais, coletivos, processuais, previdenciários e fiscalização trabalhista no campo rural. Esta lei aproximou os direitos do trabalhador rural aos direitos do trabalhador urbano (PAIDA, 2012).

Este estatuto foi promulgado num momento de conflitos sociais crescente em torno do problema da terra que teve início na década de 1960. Mobilizados pelas ligas camponesas ${ }^{7}$ e outras entidades de caráter classistas decidido a lutar por melhores condições de vida (FERRANTE, 1976). Não foi uma atitude consciente e concreta de atendimento aos problemas das relações de trabalho rural, mas o reconhecimento oficial da gravidade do problema agrário que tinha atingido um ponto que era necessário algumas soluções (FERRANTE, 1976).

Atendendo às reivindicações dos trabalhadores rurais, neste ano de 1963, o Presidente João Goulart criou, por meio da Lei n. 4.212, de 2 de março de 1963, o Fundo de Assistência ao Trabalhador Rural (Funrural), que incluiu essa categoria profissional nos benefícios previdenciários. Essa foi a primeira regulamentação específica e abrangente no direito brasileiro acerca do trabalhador rural (SILVA, 1999). Esta lei tratou pormenorizadamente de todos os aspectos trabalhistas referentes a esse trabalhador em seu artigo $2^{\circ}$, em que acentuava que trabalhador rural "[...] é toda a pessoa física que presta serviços a empregador rural, em propriedade rural ou prédio rústico, mediante salário pago em dinheiro ou in natura, ou parte in natura e parte em dinheiro" (BRASIL, 1963).

Santa Casa de Misericórdia de Santos: Foi fundada por Brás Cubas em 1543. Tendo sido inspirada nas Misericórdias de Portugal. Era chamada de Hospital de Todos os Santos. Nome que foi adotado pela cidade. Brás Cubas foi provedor por 49 anos.

${ }^{7}$ Ligas Camponesas: As Ligas Camponesas foram um movimento de luta pela reforma agrária e da melhoria das condições de vida no campo no Brasil. Foram organizações de camponeses formadas pelo Partido Comunista Brasileiro (PCB) iniciado a partir de 1945. Criadas inicialmente no estado de Pernambuco, posteriormente na Paraíba, no estado do Rio de Janeiro, Goiás e em outras regiões do Brasil.
Art. 158. Fica criado o "Fundo Assistência e Previdência do Trabalhador Rural", que se constituirá de $1 \%$ (um por cento) do valor dos produtos agropecuários colocados e que deverá ser recolhido pelo produtor, quando da primeira operação, ao Instituto de Aposentadoria e Pensões dos Industriários, mediante guia própria, até quinze dias daquela colocação.

Mas essas conquistas, na prática, não foram concretizadas: faltaram recursos financeiros, e os trabalhadores rurais continuaram sem os direitos previdenciários (BRUMER, 2002).

Foi durante o regime militar brasileiro (1964-1985), conservador, centralizador e autoritário, que houve alguns avanços. Nesse período, expandiu-se aos trabalhadores rurais a cobertura do sistema previdenciário, aprovou-se o Decreto-Lei ${ }^{\circ} 276$, de 11 de novembro de 1966, que reformulou o Estatuto do Trabalhador Rural e o adequou a suas reais possibilidades (SCHIEFELBEIN, 2011). Outra alteração significativa do governo militar foi o Decreto-Lei $\mathrm{n}^{\circ} 564$, de $1^{\circ}$ de maio de 1969 , que criou o Plano Básico da Previdência Social, restabelecendo outros benefícios.

Com esse decreto-lei, ocorreu um avanço nos direitos dos trabalhadores rurais; o dispositivo estendeu a previdência social ao trabalhador rural, principalmente aos empregados do setor agrário da agroindústria canavieira, por meio de um plano básico. Ainda em 1969, o Decreto-Lei no 704, de 24 de julho, complementou e ampliou o Plano Básico da Previdência Social Rural aos empregados das empresas produtoras, aos fornecedores de produtos agrários in natura e aos empreiteiros que utilizassem mão de obra para produção e fornecimento de produtos agrários. Também naquele ano as empresas passaram a recolher a contribuição previdenciária sobre o trabalho autônomo, mas os objetivos não foram atingidos de maneira satisfatória, levando o governo a buscar novas iniciativas no campo da previdência social rural (BELTRÃO; OLIVEIRA; PINHEIRO, 2000).

Note-se ainda o que efetivamente marcou a viabilização do sistema rural foi a Lei Complementar ${ }^{\circ} 11$, de 25 de maio de 1971, que criou, no lugar dos programas anteriores, o Programa de Assistência ao Trabalhador Rural (Prorural), produto de um Estado Autoritário que de certa forma representou um projeto avançado (FERRANTE, 1976). Beneficiava com a aposentadoria por idade, aposentadoria por invalidez e auxílio-doença, no valor de meio salário mínimo apenas para o arrimo da família (o que 
praticamente excluía as mulheres). Elas eram consideradas dependentes do marido, restava o benefício de pensão por morte, do auxílio funeral e do auxílio-reclusão, também no valor de meio salário mínimo.

A lei não previa a contribuição dos trabalhadores rurais, mas sim a aposentadoria por velhice, invalidez, pensão e auxílio-funeral; o valor era de metade do salário mínimo. Além disso, previa o direito ao serviço social e de saúde. Saliente-se que foi por meio dessa lei que os trabalhadores rurais passaram a ser segurados da Previdência Social (CASTRO; LAZZARI, 2005).

Nos anos seguintes, foram sendo aperfeiçoados direitos e benefícios dos trabalhadores brasileiros. Ainda segundo Schiefelbein (2011, p.21):

Até o ano de 1977 os beneficiários da Previdência rural e urbana eram assistidos por dois órgãos distintos: o Funrural e o INPS (Instituto Nacional de Previdência Social) os quais eram responsáveis pela assistência médica, assistência social, prestação de benefícios e por toda a estrutura administrativa e financeira dos seus programas. Com a criação do Sistema Nacional de Previdência e Assistência Social (SINPAS) através da Lei 6.439 de 1 de setembro de 1977 as duas clientelas passam a ser unificadas e cada função passou a ser de um órgão específico.

O marco da objetivação democrática e social do Estado Brasileiro foi a Constituição Federal de 1988, que alargou o tratamento constitucional dado à Previdência Social, dispondo pela primeira vez do termo "seguridade social" como sendo um conjunto de ações integradas envolvendo saúde, assistência e previdência social (HOMCI, 2009).

\section{SEgURAdo ESPECIAL: ENTRE A LEI E A PRáTICA}

Segurado especial é aquele trabalhador rural cuja produção do trabalho é feita para a economia familiar, não utilizando assim da mão de obra assalariada. Nessa categoria, incluem-se os cônjuges, companheiros e os seus filhos com idade maior que 16 anos, desde que trabalhem com a família em atividades rurais.

A Constituição de 1988 trouxe uma cobertura ampla e equitativa entre os trabalhadores urbanos e rurais e introduziu o princípio do acesso universal de idosos e inválidos, de ambos os sexos, à previdência social (DELGADO; CARDOSO JÚNIOR, 2000). Extinguiu-se o tratamento diferenciado dos trabalhadores rurais em relação aos urbanos (FERNANDES, 2005). Pelo menos conforme a Constituição.

Várias mudanças importantes e significativas foram implantadas com a nova Constituição, como:

- O valor do benefício para aposentadorias e pensões passou a ser de um salário mínimo federal;

- As mulheres trabalhadoras rurais passaram a ter direito à aposentadoria;

- A idade de acesso à aposentadoria para os trabalhadores rurais ficou estabelecida em 60 anos para homens e 55 para mulheres; e

- A comprovação do tempo de atividade rural passou a ser documentada e exigida na mesma extensão que o período de contribuição mínimo previsto para os segurados urbanos (SCHWARTZER, 2000; FERNANDES, 2005).

Houve uma reconfiguração no direito previdenciário, sendo criado o INSS, por meio do Decreto ${ }^{\circ}$ 99.350, de 27 de junho de 1990, que passou a ser responsável pela previdência social. $\mathrm{O}$ instituto tem a finalidade de cobrar as contribuições e a conceder os benefícios.

$\mathrm{O}$ marco fundamental destas mudanças, foram as leis $\mathrm{n}^{\text {os }} 8.212$ e 8.213, ambas de 24 de julho de 1991, que instituem a condição de segurado especial aos trabalhadores rurais e produtores que trabalham individualmente ou em regime de economia familiar (SCHIEFELBEIN, 2011). Outra conquista importante foram os critérios do segurado especial, em decorrência do desgaste físico derivado do seu trabalho, teve a idade da aposentadoria diminuída em cinco anos em relação ao trabalhador urbano. Sendo que para a mulher a idade é de 55 anos e para o homem é de 60 anos. Essas leis, assim trataram os segurados especiais:

VII - como segurado especial: a pessoa física residente no imóvel rural ou em aglomerado urbano ou rural próximo a ele que, individualmente ou em regime de economia familiar, ainda que com o auxílio eventual de terceiros a título de mútua colaboração, na condição de:

a) produtor, seja proprietário, usufrutuário, possuidor, assentado, parceiro ou meeiro outorgados, comodatário ou arrendatário rurais, 
que explore atividade:

1. agropecuária em área de até 4 (quatro) módulos fiscais; ou

2. de seringueiro ou extrativista vegetal que exerça suas atividades nos termos do inciso XII do caput do art. $2^{2}$ da Lei $\mathrm{n}^{\circ}$ 9.985, de 18 de julho de 2000, e faça dessas atividades o principal meio de vida;

b) pescador artesanal ou a este assemelhado, que faça da pesca profissão habitual ou principal meio de vida; e

c) cônjuge ou companheiro, bem como filho maior de 16 (dezesseis) anos de idade ou a este equiparado, do segurado de que tratam as alíneas $a$ e $b$ deste inciso, que, comprovadamente, trabalhem com o grupo familiar respectivo.

$\S 1^{\circ}$ Entende-se como regime de economia familiar a atividade em que o trabalho dos membros da família é indispensável à própria subsistência e ao desenvolvimento socioeconômico do núcleo familiar e é exercido em condições de mútua dependência e colaboração, sem a utilização de empregados permanentes.

\section{$[\ldots]$}

$\S$ 7ㅇ Para serem considerados segurados especiais, o cônjuge ou companheiro e os filhos maiores de 16 (dezesseis) anos ou os a estes equiparados deverão ter participação ativa nas atividades rurais do grupo familiar.

$\S 8^{\circ} \mathrm{O}$ grupo familiar poderá utilizar-se de empregados contratados por prazo determinado ou trabalhador de que trata a alínea $g$ do inciso $\mathrm{V}$ do caput deste artigo, em épocas de safra, à razão de no máximo 120 (cento e vinte) pessoas/dia no ano civil, em períodos corridos ou intercalados ou, ainda, por tempo equivalente em horas de trabalho (BRASIL, 1991a).

Para acessar o benefício mínimo de um salário mínimo, os trabalhadores rurais devem comprovar tempos variados de trabalho em regime de economia familiar sem subordinação a empregador conforme o benefício. Sendo que para a aposentadoria por idade são 180 meses ou 15 anos (GARCIA, 2013; BRUGNHARA, 2014).

Nota-se que uma complexidade de normas forma o arcabouço legislativo que regula a concessão dos benefícios aos segurados rurais, a começar pelo seu enquadramento, que possui regras muito subjetivas, inclusive estabelecendo tratamento diferenciado entre a contribuição do trabalhador rural e do urbano.

De acordo com a Carta Magna, os trabalhadores em regime de economia familiar, categoria que engloba os assentados da reforma agrária, não são obrigados a contribuir de maneira direta ao INSS. Tais direitos, em que pesem as discussões atuais, são frutos de muita luta e até de mortes de trabalhadores rurais durante o período que precede a Constituinte de 1988.

O caráter indireto da contribuição previdenciária dos trabalhadores rurais fica evidenciado no art. $195, \S 8^{\circ}$, da Constituição Federal. Nota-se que a contribuição será de acordo com o resultado da comercialização de sua produção:

Art. 195. A seguridade social será financiada por toda a sociedade, de forma direta e indireta, nos termos da lei, mediante recursos provenientes dos orçamentos da União, dos estados, do Distrito Federal e dos Municípios, e das seguintes contribuições sociais:

[...] $\S 8^{\circ} \mathrm{O}$ produtor, o parceiro, o meeiro, arrendatário rural e o pescador artesanal, bem como os respectivos cônjuges, que exerçam suas atividades em regime de economia familiar, sem empregados permanentes, contribuirão para a seguridade social mediante a aplicação de uma alíquota sobre o resultado da comercialização da produção e farão jus aos benefícios nos termos da lei (BRASIL, 1988).

Observa-se que passados 30 anos da promulgação da Constituição, muitos ainda desconhecem a existência desses direitos, inclusive os próprios trabalhadores em regime de agricultura familiar. Isso cria para os interessados muitas dificuldades no resgate de seus direitos, quer pelas exigências feitas pelo INSS, quer pela recusa do agente federal no recebimento de certos documentos como prova do trabalho rural (GARCIA, 2013).

As normativas editadas pelo INSS, que, na maioria das vezes, são explicativas, dão margem a muitos erros de interpretação; um exemplo claro é a instrução normativa INSS/PRES no 77, de 21 de janeiro de 2015, que continua exigindo dos trabalhadores rurais em regime familiar a apresentação de duas declarações de exercício de atividade rural para entrarem com pedido de solicitação de benefícios previdenciários, ou a 
comprovação dos 180 meses (quinze anos) trabalhados com provas materiais de que são segurados especiais. A declaração deverá ser fornecida pelo sindicato dos trabalhadores rurais na agricultura familiar, na falta deste, pelas autoridades competentes para fornecer estas declarações, Juízes de Direito, Representante do Ministério Público, Delegados de Polícia e Diretores de Escolas (ELIZIÁRIO, 2009).

Por determinação do INSS, de acordo com a Normativa $n^{\circ} 77$, não são aceitas declarações emitidas por órgãos públicos: Coordenadoria de Assistência Técnica Integral (CATI), para os agricultores da agricultura familiar em geral, a Fundação Itesp, para os beneficiários da reforma agrária estadual (Estado de São Paulo), e o Instituto Nacional de Colonização e Reforma Agrária (INCRA), para os beneficiários da reforma agrária federal.

Constata-se, que os agricultores familiares não conseguem acessar administrativamente seus benefícios previdenciários, tendo de recorrer ao Judiciário para terem seus direitos reconhecidos, tornando demorado o acesso ao benefício. Muitas vezes, precisam recorrer à prova exclusivamente testemunhal, o que desperta grande controvérsia em matéria previdenciária (GARCIA, 2013). Nessa mesma perspectiva, salienta Garcia (2013, p. 173) que: "os segurados rurais das diversas categorias, de um modo geral, encontram dificuldade na obtenção de provas do exercício de atividade laborativa no campo".

No que concerne à contribuição do Segurado Especial à Previdência Social, delimita-se que, embora muitos achem que não há contribuição, os segurados especiais contribuem sim para a Previdência Social. Sua contribuição é feita em decorrência da venda de sua produção agropecuária. Os valores pagos são de $2,1 \%$ da receita da venda obtida de sua produção, sendo $2 \%$ destinados à seguridade social e $0,1 \%$ ao financiamento das prestações a serem pagas em virtude de acidentes de trabalho, conforme explicitado na Lei $\mathrm{n}^{\circ} 8.212 / 91$.

A responsabilidade pelo preenchimento da guia e pelo recebimento da contribuição previdenciária do segurado especial é do comprador, quando feita por pessoa jurídica. Quando a comercialização for feita no varejo, para consumidores pessoas físicas, a responsabilidade é do segurado especial, o que na maioria das vezes não acontece. Assim, somente são isentos de contribuição os produtores rurais que produzem somente para sua subsistência, devendo ser comprovado esta condição. Em termos processuais, infere-se que, para conseguir fazer as contribuições, o segurado especial tem de fazer um cadastro no INSS e provar a sua condição de segurado especial, passando pelos mesmos problemas de apresentação de provas de quando vão requerer benefícios junto ao INSS.

Quanto aos riscos da perda da condição de segurado especial, percebe-se que a atividade laborativa no meio rural é penosa e geralmente desvalorizada. Assim, a cada dia essa categoria procura desenvolver novos meios para melhorar sua renda e fortalecer-se. É constante a preocupação do agricultor familiar em saber se continua com seu direito de segurado especial exercendo determinada atividade.

De acordo com o art. 10 da Lei $n^{\circ} 11.718 / 2008$, que acresceu o $\S 8^{\circ}$ ao art. 11 da Lei $n^{0} 8.213 / 91$, o produtor rural não perde a condição de segurado especial se:

I - a outorga, por meio de contrato escrito de parceria, meação ou comodato, de até 50\% (cinquenta por cento) de imóvel rural cuja área total não seja superior a 4 (quatro) módulos fiscais, desde que outorgante e outorgado continuem a exercer a respectiva atividade, individualmente ou em regime de economia familiar;

II - a exploração da atividade turística da propriedade rural, inclusive com hospedagem, por não mais de 120 (cento e vinte) dias ao ano;

III - a participação em plano de previdência complementar instituído por entidade classista a que seja associado em razão da condição de trabalhador rural ou de produtor rural em regime de economia familiar; e

IV - ser beneficiário ou fazer parte de grupo familiar que tem algum componente que seja beneficiário de programa assistencial oficial de governo; $\mathrm{e}$

VI - a associação em cooperativa agropecuária (BRASIL, 1991b).

Por outro lado, o produtor rural perde a condição de segurado especial se tiver outras fontes de renda que sejam superiores a um salário mínimo. É importante frisar que os segurados especiais têm de ter como atividade exclusiva a agricultura familiar, para perder esse direito . Exceto aposentadoria por idade rural. E muitas vezes, o trabalhador em regime de economia familiar, por desconhecimento, e com o objetivo de ser segurado da previdência social, faz contribuição facultativa, perdendo assim a 
condição de segurado especial.

Por desconhecer seus direitos, muitos trabalhadores deixam de reivindicar os benefícios previdenciários a que fazem jus. Ignoram também que a perda de seus direitos ocorre no dia seguinte aos prazos estabelecidos na Lei $n$. 10.118/2008. O segurado especial conserva seus direitos aos benefícios de acordo com o art. $15, \S 3^{\circ}$, da Lei $\mathrm{n}^{\circ} 8.213 / 91$, quando:

Art. 15. Mantém a qualidade de segurado, independentemente de contribuições:

I - sem limite de prazo, quem está em gozo de benefício;

II - até 12 (doze) meses após a cessação das contribuições, o segurado que deixar de exercer atividade remunerada abrangida pela Previdência Social ou estiver suspenso ou licenciado sem remuneração.

III - até 12 (doze) meses após cessar a segregação, o segurado acometido de doença de segregação compulsória;

IV - até 3 (três) meses após o licenciamento, o segurado incorporado às Forças Armadas para prestar serviço militar (BRASIL, 1991b).

Em relação aos dependentes do segurado especial, há três classes deles. Seguindo a norma geral da Lei ${ }^{\circ}$ 8.213/91, em seu art. 16, são dependentes:

I - o cônjuge, a companheira, o companheiro e o filho não emancipado, de qualquer condição, menor de 21 (vinte e um) anos ou inválido;

III - o irmão não emancipado, de qualquer condição, menor de 21 (vinte e um) anos ou inválido;

$\S 1^{\circ}$ A existência de dependente de qualquer das classes deste artigo exclui do direito às prestações os das classes seguintes.

$\S 2^{\circ}$. O enteado e o menor tutelado equiparam-se a filho mediante declaração do segurado e desde que comprovada a dependência econômica na forma estabelecida no Regulamento.

$\S 3^{\circ}$ Considera-se companheira ou companheiro a pessoa que, sem ser casada, mantém união estável com o segurado ou com a segurada, de acordo com o $\S 3^{\circ}$ do art. 226 da Constituição Federal.

$\S 4^{\circ} \mathrm{A}$ dependência econômica das pessoas indicadas no inciso I é presumida e a das demais deve ser comprovada (BRASIL, 1991b).

Para ter direito ao benefício previdenciário, os dependentes precisam comprovar a dependência por meio de documentos que comprovem a dependência econômica dos pais, do irmão não emancipado ou de outros membros da família menores de 21 anos ou inválido. Essa é a classe que mais enfrenta dificuldades na obtenção de benefícios previdenciários, visto que os funcionários do INSS exigem documentos que os dependentes muitas vezes não possuem. Citamos, por exemplo, as filhas solteiras dos agricultores familiares que engravidam e ao solicitarem o salário maternidade, lhes sãoexigidas notas de venda de produtos agropecuários em seu nome: e, não havendo, é-lhes negado o benefício, sendo que, dessa forma, o solicitante se vê obrigado a buscar o judiciário para ter seus direitos reconhecidos.

Outra dimensão de dificuldades que passa o assentado é a prova da identidade rural. Garcia (2013) informa que, os segurados rurais das diversas categorias, de um modo geral, encontram dificuldade na obtenção de provas do exercício de atividade laborativa no campo. O grande problema é que muitos documentos exigidos são de tempos passados e a chamada prova contemporânea do tempo, em que se deseja provar a condição de segurado especial, torna tudo muito mais difícil. Se alguém desejar provar que há dez anos era trabalhador rural em regime de agricultura familiar, necessita de algum tipo de prova material daquela época, como, por exemplo, um contrato de arrendamento, um bloco de notas de produtor rural, nota de compra de insumo agrícola, etc. Essa é a grande limitação, já que muitos não possuem o "arquivo morto" e muitas vezes nem sabem que são segurados especiais da previdência. Além disso, são muito comuns situações em que os contratos foram realizados verbalmente ou em que o comércio dos insumos era feito informalmente. Consequentemente, muitas vezes esses trabalhadores rurais possuem direitos líquidos e certos, mas não conseguem obtê-los por conta da falta de provas documentais.

Assim, é necessário buscar no Poder Judiciário o reconhecimento de seus direitos, ainda que isso consuma tempo desnecessário. Quem o faz, obtém êxito, o que comprova a legalidade do pedido. Durante esse processo, vários documentos apresentam potencial comprobatório; assim, os documentos que comprovam a atividade rural são os chamados documentos de prova 
plena, de acordo com a nova redação do art. 106 da Lei no 8.213/91, dada pela Lei $n^{\circ} 11.718 / 2008$ :

Art. 106. A comprovação do exercício de atividade rural será feita, alternativamente, por meio de:

I - contrato individual de trabalho ou Carteira de Trabalho e Previdência Social;

II - contrato de arrendamento, parceria ou comodato rural

III - declaração fundamentada de sindicato que represente o trabalhador rural ou, quando for o caso, de sindicato ou colônia de pescadores, desde que homologada pelo Instituto Nacional do Seguro Social - INSS;

IV - comprovante de cadastro do Instituto Nacional de Colonização e Reforma Agrária - INCRA, no caso de produtores em regime de economia familiar;

$\mathrm{V}$ - bloco de notas do produtor rural;

VI - notas fiscais de entrada de mercadorias, de que trata o $§ 70$ do art. 30 da Lei no 8.212 , de 24 de julho de 1991, emitidas pela empresa adquirente da produção, com indicação do nome do segurado como vendedor;

VII - documentos fiscais relativos à entrega de produção rural à cooperativa agrícola, entreposto de pescado ou outros, com indicação do segurado como vendedor ou consignante

VIII - comprovantes de recolhimento de contribuição à Previdência Social decorrentes da comercialização da produção

IX - cópia da declaração de imposto de renda, com indicação de renda proveniente da comercialização de produção rural;

X - licença de ocupação ou permissão outorgada pelo Incra (BRASIL, 2008).

Mesmo apresentando esses documentos, o INSS muitas vezes indefere o pedido de benefício previdenciário aos agricultores em regime de agricultura familiar. Visto que as leis e as normas são interpretadas erroneamente pelos agentes do INSS.
No caso das mulheres, é ainda mais difícil o reconhecimento de sua condição de segurado especial, pois, de acordo com o art. $55, \S 3^{\circ}$, da Lei $\mathrm{n}^{\mathrm{o}} 8.213 / 91$ :

$\S 3^{\circ}$ - A comprovação do tempo de serviço para os efeitos desta Lei, inclusive mediante justificação administrativa ou judicial, conforme o disposto no art. 108, só produzirá efeito quando baseada em início de prova material, não sendo admitida prova exclusivamente testemunhal, salvo na ocorrência de motivo de força maior ou caso fortuito, conforme disposto no Regulamento (BRASIL, 1991b).

Assim, o INSS, ao exigir provas materiais das mulheres, torna mais difícil a comprovação, principalmente os documentos comprobatórios da profissão de lavradora, posto que na maioria dos seus documentos a profissão vem anotada como sendo "do lar" ainda que se dedique aos afazeres rurícolas. De acordo com o art. 136, $\S 1^{\circ}$, da Instrução Normativa $n^{\circ} 11 / 2006$, são subsídios para a homologação da declaração dos sindicatos documentos que comprovam a atividade rural. O INSS tem liberdade para analisar e homologar a declaração dos sindicatos dos trabalhadores em regime de economia familiar ou rejeitá-la, desde que justifique tal rejeição, devendo analisar todos os documentos que o segurado possuir. Mas, na maioria das vezes, os funcionários, por desconhecimento da legislação e falta de boa vontade, não homologam a declaração do sindicato. Contemporaneamente, é pacífico o entendimento de que os assentados são trabalhadores em regime de agricultura familiar e, por consequência, segurados especiais. Todas as vezes em que os segurados especiais buscam o judiciário para que seus direitos sejam reconhecidos, o INSS tem procurado contestar argumentando acerca da ineficaz prova apresentada pelo segurado à autarquia. A lide tem sido resolvida pela Justiça em favor dos agricultores familiares.

\section{Metodologia: os CAMinhos da PESQUisa}

Para o presente trabalho, foi escolhido o método exploratório e as estratégias de pesquisa foram quantitativas e qualitativas. Os instrumentos utilizados para a coleta de dados foram questionários estruturados e entrevistas semiestruturadas, aplicados a 57 pessoas dos 42 lotes que recebem benefícios previdenciários. Com assentados que não dispõem do benefício previdenciário foram feitas 10 entrevistas. A técnica de abordagem foi por meio de entrevistas semidiretivas, nas quais foram usados como 
fonte secundária os dados da caderneta de campo de 2014 (levantamento de produção agropecuária e sociais feito pela Fundação ITESP em todos os assentamentos estaduais a cada dois anos), consultas a bancos de dados da Fundação ITESP e a experiência profissional do pesquisador (diário de campo), além de dissertações, artigos e livros relacionados ao tema em questão. Esses dados irão colaborar para o entendimento de todo o contexto que está sendo estudado.

A opção pelo tema dos direitos previdenciários rurais em um assentamento derivou das experiências vividas pelo pesquisador como técnico em desenvolvimento agrário na Fundação Instituto de Terras do Estado de São Paulo (Itesp); dentre as funções desenvolvidas estava o atendimento aos agricultores assentados. Assim, as atividades executadas permitiram o acúmulo institucional do conhecimento sobre a vivência, a dinâmica, as relações e inter-relações estabelecidas no interior de assentamentos rurais.

Com certeza, para levar a bom termo o estudo, o autor precisou se despojar da visão do técnico e aprender, passo a passo, a difícil tarefa de ser pesquisador. Em uma conjuntura na qual a reforma da previdência tem ocupado grandes manchetes, é preciso rediscutir, na universidade, o significado que tem a conquista destes direitos e a importância que a aposentadoria tem para milhares de brasileiros. Antes da discussão da reforma da previdência ocupar o cenário nacional, estudei, nos últimos anos, o papel da aposentadoria no modo de vida do assentamento Reage Brasil, localizado no Município de Bebedouro-SP.

\section{RESULTADOS E DISCUSSÕeS}

Um dos pontos investigados pela pesquisa foi o tipo de benefício recebido. A legislação permite que a previdência rural se materialize em aposentadoria por Idade; Aposentadoria por Invalidez; Auxílio Doença; Auxílio Acidente; Auxílio Reclusão; Pensão por Morte e Salário Maternidade. Nota-se que a aposentadoria por idade é o benefício mais comum recebido pelos segurados da comunidade pesquisada, representando $63 \%$ do total. As aposentadorias por tempo de contribuição são de beneficiários que já possuíam esse benefício ou direito, visto que é um benefício exclusivo dos trabalhadores urbanos.

Outro fato relevante da grande quantidade de aposentados por idade rural é que em 2014 completaram-se 15 anos do assentamento, tempo necessário para fazer jus à aposentadoria por idade rural. Destaca-se ainda que $12 \%$ possuem dois benefícios previdenciários, como pensão por morte e aposentadoria por idade rural.

Por conta das grandes dificuldades impostas pelo INSS e pela agência de Bebedouro, os trabalhadores do Assentamento Reage Brasil têm recorrido à Justiça para assegurar seus direitos previdenciários. Constata-se que 77\% dos benefícios foram obtidos por vias judiciais, o que é um significativo indicador de que este direito enfrenta barreiras administrativas concretas.

Segundo os entrevistados, o INSS dificulta o reconhecimento dos direitos do segurado especial; exige vários documentos e, no final, indefere o pedido do benefício, afirmando que "Vocês não pagam INSS, não têm, portanto, direito nenhum!”. Parece que há uma má vontade por parte dos funcionários do INSS.

Figura 1 - Como o benefício foi obtido

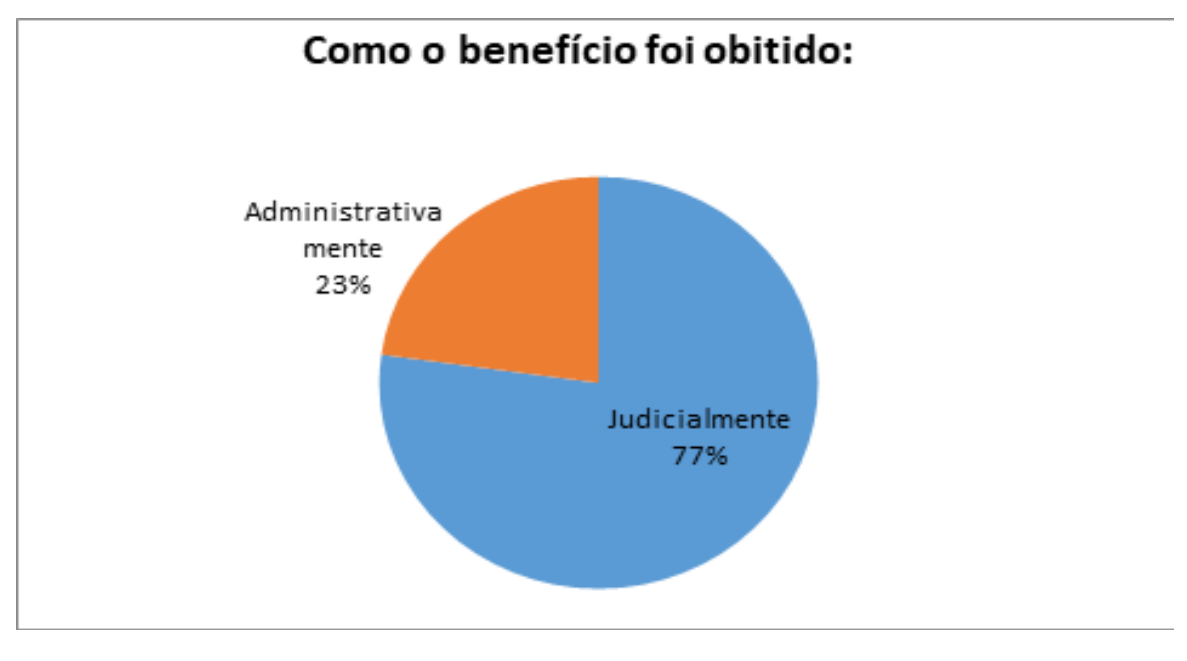

Fonte: elaborado pelos autores (2016)

Para evidenciar essa dinâmica, destaque-se que, até 2014, a comunidade não tinha quinze anos de assentamento. Logo, os trabalhadores rurais detinham dificuldades para apresentar provas dos 180 meses, conforme solicitado pela legislação. O problema continua: a unidade local do INSS está exigindo documentos de emissão de notas e compras de insumos agrícolas dos quinze anos de assentados, e muitos não guardaram tais documentos.

Por conta da necessidade de recorrer à Justiça para obter a aposentadoria, existe um lapso temporal entre a entrada e obtenção do direito, que, em média, tem sido de dez meses, mas há casos em que foram cinco anos, tal como ilustrado na Figura 2. 
Figura 2 - Tempo necessário para receber o benefício

Tempo necessário para receber o benefício

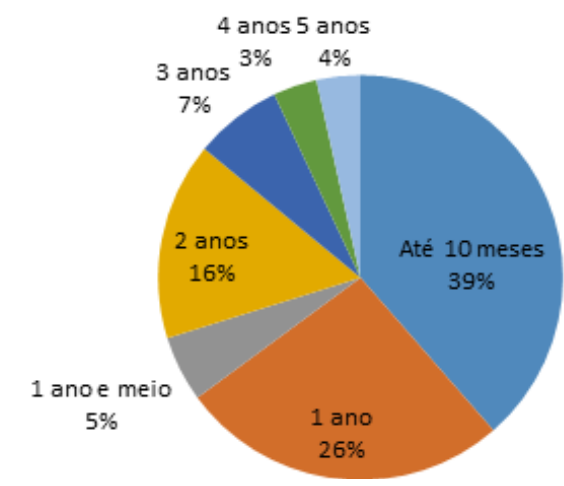

Fonte: elaborado pelos autores (2016)

Figura 3 - Identificação das áreas de aplicação do recurso

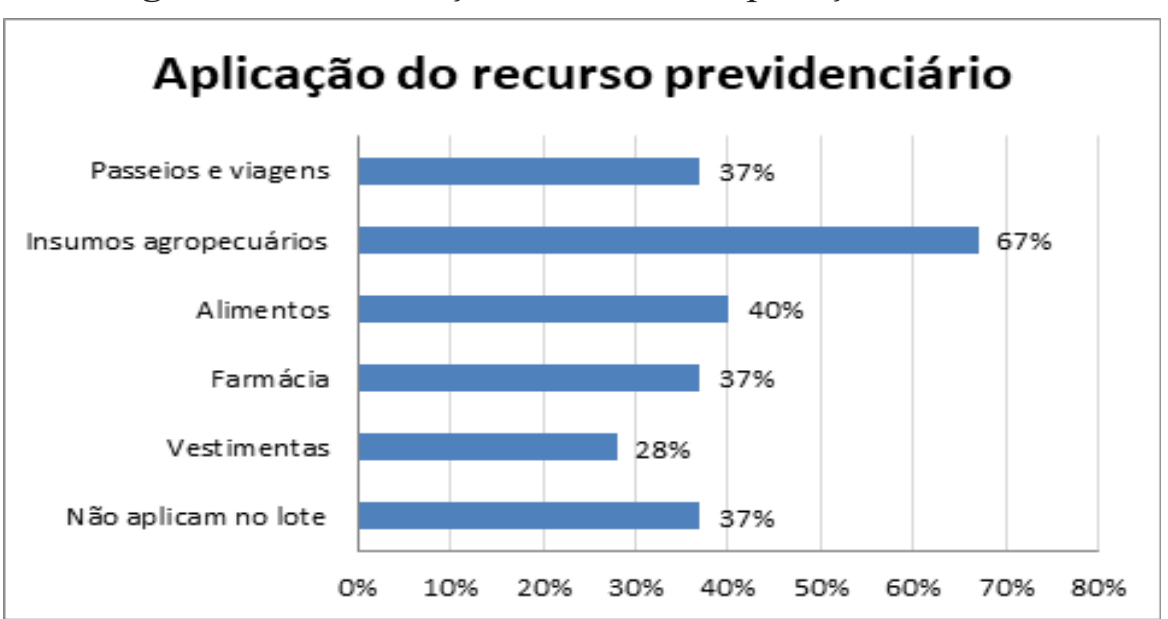

Fonte: elaborado pelos autores (2016)

Contribuindo para a análise, buscou-se verificar a avaliação que os beneficiários da previdência rural faziam sobre o atendimento da Agência Local do INSS. Das 57 famílias que possuem benefícios previdenciários, $86 \%$ declararam que o INSS não reconhece os direitos dos assentados como segurados especiais; são exigidos vários documentos e sempre acabam indeferindo o pedido de benefício previdenciário. Esses são os motivos da alta porcentagem $(82,5 \%)$ que considera insatisfatório o atendimento.

A situação agrava-se mais ainda quando o benefício é requerido por um agregado. Para o INSS, os agregados são outra família, e o órgão não reconhece os documentos apresentados em nome do titular do lote. Caso mais grave ocorre com as filhas dos assentados quando têm filhos enquanto solteiras, pois não possuem nenhum documento em seu nome que comprovem a sua condição de trabalhador em regime de agricultura familiar. Outra frente de investigação da pesquisa empírica foi a aplicação dos recursos previdenciários. Os dados apresentados (Figura 3) são interessantes, pois ajudam a dimensionar a importância dos benefícios previdenciários na composição da renda das famílias assentadas.

Considerando-se que já são $50 \%$ de lotes com benefícios previdenciários e o valor recebido é de um salário mínimo, infere-se que metade dos beneficiários já possui essa renda. Somando-se a essas informações as dificuldades da agricultura familiar por que passa o Brasil, em especial nos assentamentos rurais, conclui-se que a previdência rural vem adquirindo papel importante enquanto política social no campo. Não fica dúvida a respeito da importância dos benefícios previdenciários para as famílias assentadas, ainda que isso se contraponha aos objetivos propostos para a política da reforma agrária.

Sabe-se que o aumento da produção agropecuária está relacionado ao aumento do investimento. Conforme dados das pesquisas, esse fato vem ocorrendo na comunidade pesquisada; observa-se que $67 \%$ dos entrevistados aplicam os recursos dos benefícios na aquisição de insumos agropecuários; é comum serem usados em compras de sementes, adubos, ração etc. Podese concluir que a renda dos lotes que possuem benefícios previdenciários é superior à dos que não os têm; fato que ocorre também nas regiões Sul e Nordeste do Brasil.

Conforme foi percebido e relatado por Delgado e Cardoso Júnior (2000), o benefício tem sido utilizado até mesmo como seguro agrícola, já que $48 \%$ dos domicílios da região Sul e $43 \%$ no Nordeste são responsáveis por estabelecimentos rurais ativos, e, desses estabelecimentos, $44,7 \%$ no primeiro e $51,7 \%$ no segundo caso, declararam utilizar o benefício na manutenção e no custeio das atividades.

BENEFICIOS PREVIDENCIÁRIOS: AUMENTO DE RENDA E MELHORIA DA QUALIDADE DE VIDA DOS ASSENTADOS

De modo geral, os benefícios previdenciários são de suma importância na vida cotidiana dos assentados (Figura 4). Para 57\%, a previdência proporciona mudança nas relações familiares, tal como observado nos 
trechos das entrevistas: "hoje é possível, uma vez por mês, ir a Bebedouro com os netos, comer lanche ou pizza [...]."; "Após a aposentadoria, o dinheiro do mercado em todos os meses está garantido". Nota-se que há um aumento na qualidade de vida das famílias com a segurança alimentar, autonomia financeira e até passeios com a família.

Figura 4 - Identificação dos benefícios proporcionados pelo recurso.

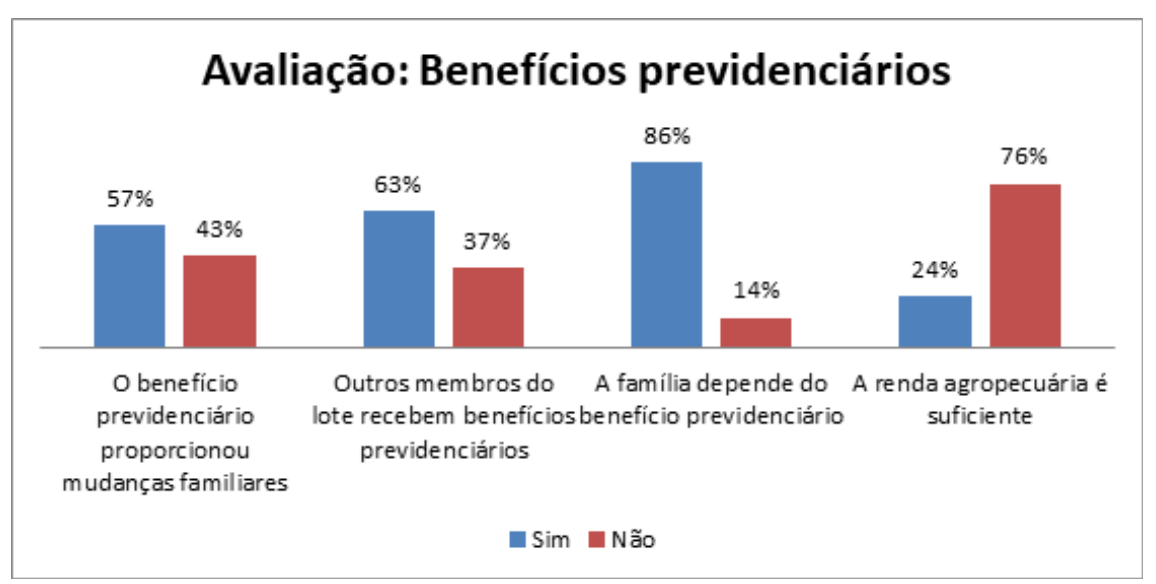

Fonte: elaborado pelos autores (2016).

Em estudo de avaliação dos impactos socioeconômicos e regionais da Previdência Social Rural nas regiões Sul e Nordeste do Brasil, Delgado e Cardoso Júnior (1999) constataram que houve um aumento na renda das famílias beneficiárias de benefícios previdenciários. A renda familiar na região do Sul é três vezes maior do que um salário mínimo, e na região Nordeste é de 1,6 salário mínimo. Mas, quando são analisados os benefícios previdenciários na Região Sul, correspondem a 41,5\% do orçamento familiar e na Região Nordeste, a 70,8\%. Pode-se concluir que os benefícios previdenciários rurais aumentam seu grau de importância conforme decresce o rendimento familiar.

Nessa mesma direção, Schwarzer (2000a), em pesquisa no Estado do Pará, Região Norte do país, constatou que os benefícios previdenciários rurais representam aproximadamente $74,5 \%$ da renda total dessas famílias, quando existe um beneficiário, e quando esse é o chefe da família, chega até a $81,7 \%$ da renda total familiar. Essas famílias dispõem, em geral, de um conjunto muito limitado de fontes de renda e ocupações (BIOLCHI, 2002).

Delgado e Cardoso Júnior (2000) acentuam que esses meios transformamse quantitativa e qualitativamente ao serem somados aos benefícios rurais, pois estes cumprem não apenas a função de seguro de proteção social, como também, indiretamente, "uma função que muito se aproxima de um seguro agrícola, e amplia o potencial produtivo da economia familiar"; e esta pesquisa chegou a conclusões semelhantes.

Nesse sentido, $76 \%$ dos entrevistados consideram que a renda obtida do lote agrícola não é suficiente para a sobrevivência da família, reiterando a importância do benefício previdenciário. Destaca-se ainda que $38 \%$ das famílias recebem outros benefícios sociais, como Bolsa Família e Renda Cidadã. Além disso, como evidenciado, a previdência rural proporciona impactos no que se refere ao nível de bem-estar e lazer das famílias com benefícios previdenciários.

\section{CONSIDERAÇOES FINAIS}

O objetivo deste artigo foi contribuir para a discussão da previdência rural em assentamentos, seus entraves e sua abertura para a reprodução social das famílias.

Notou-se que os recursos financeiros dos benefícios previdenciários, em especial as aposentadorias, são aplicados nos lotes, no lazer, no conforto e na saúde dos beneficiários. Esse recurso proporciona um aumento na renda, segurança e estabilidade para a família e agregados; consequentemente, muda a rotina e a dinâmica da vida familiar. Os beneficiários ganham status e relevância financeira e social; para as mulheres, as mudanças são ainda mais nítidas, principalmente no que tange aos gastos pessoais.

A pesquisa mostrou ainda que os recursos previdenciários estão viabilizando a permanência das famílias no assentamento; estão contribuindo para melhorar a condição social das famílias assentadas; estão sendo utilizados para a compra de insumos agropecuários para uso no lote.

Nota-se que mesmo após 30 anos da promulgação da Constituição de 1988, que trouxe direitos previdenciários positivados aos trabalhadores rurais em regime de economia familiar, estes ainda são desconhecidos pela maioria da sociedade brasileira. Foi surpreendente no estudo a avaliação da atitude dos agentes do INSS, que demonstram, uma má compreensão da lei, insistindo que os trabalhadores em regime de economia familiar não possuem direitos previdenciários. 
Este artigo teve como meta pôr em questão o alcanço e as obstruções da previdência social rural no Brasil, na comunidade estudada, os direitos do segurado especial, suas dificuldades de comprovação juto ao INSS e efeitos dos benefícios previdenciários no território. Foi uma contribuição de quem aprendeu a ver, além dos dados imediatos, as perspectivas e os limites da aquisição da aposentadoria em um território, utilizando parâmetros de metodologia científica, e com o objetivo de não incorrer em erros de interpretação.

\section{REFERÊNCIAS}

BRASIL. Constituição Federal da República Federativa do Brasil (1988). Diário Oficial [da] República Federativa Brasil, Poder Executivo, Brasília, 1988.

Lei n ${ }^{\circ} 8.212$, de 24 de julho de 1991. Dispõe sobre a organização da Seguridade Social institui Plano de Custeio e dá outras providências. Diário Oficial [da] República Federativa Brasil, Poder Executivo, Brasília, 25 de julho de 1991a.

Lei $n^{\circ} 8.213$, de 24 de julho de 1991. Dispõe sobre os Planos de Benefícios da Social e dá outras providências. Diário Oficial [da] República Federativa Brasil, Poder Executivo, Brasília, 25 de julho de 1991b.

BRUMER, A. Previdência social rural e gênero. Sociologias, Porto Alegre, V. 4, n. 7, p. 50-81, 2002.

BRUGNHARA, A. C. A previdência Social Rural e os Quilombolas: Uma Análise Desse Direito no Vale do Ribeira-SP. 2014. 184 f. Dissertação (Mestrado em 2014), Universidade Federal Rural do Rio de Janeiro, Instituto de Ciências Humanas e Sociais, Rio de janeiro, 2014. Disponível em: <http://r1.ufrrj.br/cpda/wp-content/uploads/2014/10/Vers\%C3\%A3oFinal_Revisada_Impressa-1.pdf $>$. Acesso em: 01 nov. 2016.

DELGADO, G.; CARDOSO JÚNIOR, J. C. Principais resultados da pesquisa domiciliar sobre a previdência rural na região sul do Brasil: projeto avaliação socioeconômica da previdência social rural. Rio de
Janeiro, 2000.

. O idoso e a previdência rural no Brasil: a experiência recente de universalização. Brasília: IPEA, 1999.

ELIZIÁRIO, R. O. Os Trabalhadores Rurais em Regime de Agricultura Familiar e seus Direitos como Segurados Especiais Junto ao INSS. Trabalho de Conclusão de Curso (Graduação em 2009), Faculdades Integradas Unifafibe, Bebedouro, 2009.

FERNANDES, A. Previdência social rural: considerações sobre aposentadorias rurais no Assentamento Monte Alegre I. 2005. Trabalho de Conclusão de Curso (Pós Graduação em 2005), Universidade Federal Rural de Pernambuco, Recife, 2005.

FERRANTE, V. L. S. B. O estatuto do trabalhador rural e o Funrural: ideologia e realidade. Perspectivas: Revista de Ciências Sociais, v. 1, 1976.

HOMCI, A. L. A evolução histórica da previdência social no Brasil. Revista Jus Navigandi, Teresina, v. 14, n. 2104, 2009. Disponível em: <https://jus. com.br/artigos/12493>. Acesso em: 24 set. 2016.

IBGE - Instituto Brasileiro de Geografia e Estatística. Portal Cidades. Brasília-DF, 2016. Disponível em: <http://www.cidades.ibge.gov.br/xtras/ home.php>. Acesso: 12 out. 2016.

INSS - Instituto Nacional do Seguro Social. Instrução Normativa no $77-$ 2015 do INSS. Disponível em: <https://previdenciarista.com/in-77-2015/>. Acesso: 12 out. 2016.

ITESP - Instituto de Terras do Estado de São Paulo. Caderno de Campo, Dados Secundários, 2014.

OLIVEIRA, A. S. Assentamentos rurais em hortos florestais da região norte do Estado de São Paulo. 2006. 96 f. Dissertação (Mestrado em Desenvolvimento Regional e Meio Ambiente), Centro Universitário de Araraquara, Araraquara, 2006. Disponível em: <http://www.uniara.com.br/ arquivos/file/cursos/mestrado/desenvolvimento_regional_meio_ambiente/ 
dissertacoes/2006/alessandro-silva-de-oliveira.pdf>. Acesso em: 11 nov. 2016.

PAIDA, Z. Trabalhador Rural. Conteúdo Jurídico. BrasíliaDF: 2012. Disponível em: <http://www.conteudojuridico.com. $\mathrm{br} /$ ?artigos\&ver=2.36550\&seo=1>. Acesso em: 19 ago. 2017.

SCHIEFELBEIN, A. Os impactos sociais e econômicos da previdência social rural no município de Silveira Martins, RS. 2011.93 f. Dissertação (Mestrado em Geografia) - Universidade Federal de Santa Maria, 2011. Disponível em: <http://cascavel.ufsm.br/tede//tde busca/arquivo. php? $\operatorname{cod}$ Arquivo=3860> . Acesso em: 11 nov. 2016.

SCHWARZER, H. Previdência rural e combate à pobreza no Brasil Resultados de um estudo de caso no Pará. Estudos Sociedade e Agricultura, Rio de Janeiro, n. 14, p. 72-102, abr. 2000.

THEODORO, M.; DELGADO, G. C. Política Social: Universalização ou Focalização. Políticas Sociais - Acompanhamento e Análise. Brasília: IPEA, 2003.

\section{PROJETO JAÍBA - ETAPA I: ASSENTAMENTO E CONCENTRAÇÃO DA TERRA EM UM PERÍMETRO IRRIGADO}

Adâmara Santos Gonçalves Felício ${ }^{1}$ Bastiaan Philip Reydon

RESUMo: Este trabalho tem como objetivo analisar o processo de concentração da terra em perímetros irrigados do semiárido. A concentração da terra no Semiárido é de sobremaneira elevada, explicada pelo contexto histórico do processo de ocupação. Na década de 1960, a questão acerca da distribuição da terra no país e a necessidade de uma política em prol do desenvolvimento regional, fomentou debates e políticas públicas, dentre elas o desenvolvimento da agricultura irrigada, através dos perímetros públicos de irrigação, mediante a interação entre famílias assentadas e empresários agrícolas. No entanto,em muitos perímetros irrigados, tal proposta não vigorou. Destarte, o problema de pesquisa visa analisar o processo de concentração da terra em perímetros irrigados, através do estudo de caso do Projeto Jaíba Etapa I. A hipótese que norteia o estudo está baseada no argumento que permaneceram na terra, alguns poucos produtores bem-sucedidos, que encontraram oportunidade em um determinado nicho de mercado, incorrendo estes na compra de lotes daqueles que optaram em não cultivar a terra recebida. Como resultante da pesquisa realizada, compreendeu-se que falhas no processo de seleção dos assentados e endividamento, foram determinantes para a desistência de muitos assentados, criando um ambiente propício a negociação dos lotes recebidos, em um processo informal de transferência de direitos, capaz de reorientar a ocupação original do assentamento, fazendo com que o objetivo inicial não fosse cumprido, mas sim, ocorresse um processo de concentração da terra irrigada, seja através de assentados que conseguiram viabilizar o cultivo ou através de agricultores regionais que enxergaram o perímetro irrigado como uma alternativa para o desenvolvimento da fruticultura em meio ao semiárido, através do mercado de terras informal.

Graduada em Ciências Econômicas pela PUCCAMPINAS, Mestra em Desenvolvimento Econômico pelo IE/ UNICAMP e Doutoranda em Desenvolvimento Econômico pelo IE/UNICAMP. Filiação: Instituto de Economia - UNICAMP.

Professor Titular da Universidade Estadual de Campinas, professor visitante - International Center for Land Policy Studies and Training em Taiwan e professor visitante - Utrecht University. 